\title{
Guttate endothelial changes with anterior eye inflammation
}

\author{
S. G. ZANTOS AND B. A. HOLDEN \\ From the Cornea and Contact Lens Research Unit, School of Optometry, \\ University of New South Wales, Sydney, Australia
}

SUMMARY This report details the rapid appearance and gradual disappearance of guttate endothelial changes in a patient who experienced an acute 'red eye' associated with the continuous wear of contact lenses. This episode of acute inflammation was accompanied by a diffuse corneal infiltrate, endothelial bedewing, and the guttage changes.

Guttate endothelial changes in the central cornea are characteristic of primary eye disorders such as cornea guttata and Fuchs's endothelial dystrophy. Similar guttate appearances are also commonly observed in the periphery of the cornea in the aging eye. Guttae represent excrescences of Descemet's membrane, over which endothelial cells may be attenuated or absent. ${ }^{1}$ In the early stages guttae appear with the slit-lamp as small shallow depressions in the endothelial mosaic. In later stages they appear as distinct round black holes.

Cornea guttata secondary to active ocular disease is a less well known phenomenon. Wolter and Larson $^{2}$ and Wolter ${ }^{3}$ described the occurrence of confluent guttae in the form of lines and geographic patterns in cases of long-standing luetic interstitial keratopathy. Histological studies of such cases have revealed varying degrees of correspondence between the pattern of guttae and the pattern of deep stromal vessels or posterior corneal folds. ${ }^{56}$ Endothelial changes have also been reported with a variety of other conditions involving the anterior eye. ${ }^{7-11}$ In these reports, however, the nature of these changes and the time scale for their appearance are not clear. Berliner ${ }^{12}$ described circular crevices between cells 'similar to the picture of endothelial dystrophy' occurring in the early stages of interstitial keratitis and guttate changes occurring after the acute inflammation had subsided.

Grayson $^{13}$ and Brandreth ${ }^{14}$ have both observed the endothelium to take on an appearance resembling cornea guttata during ocular inflammation, this appearance subsiding when the inflammation has

Correspondence to S. G. Zantos, Cornea and Contact Lens Research Unit, PO Box 1, Kensington, NSW 2033, Australia. passed. They have termed these episodes endothelial oedema. Inomata and Smelser, ${ }^{15}$ however, have demonstrated the rapid appearance of excrescences in Descemet's membrane in the rabbit cornea during experimentally induced uveitis.

The purpose of this paper is to report the appearance and disappearance of guttate endothelial changes in a patient during an episode of anterior eye inflammation related to continuous contact lens wear.

\section{Case history}

The patient was a 42-year-old woman of good general health. She had congenital high myopia with nystagmus, and light perception only in the left eye. She had 15 years previous experience with a daywear contact lenses in the right eye. As the patient was about to be involved in a continuous-wear contact lens programme, endothelial photographs were taken by a high-magnification slit-lamp technique. ${ }^{16}$ The endothelial appearance was normal. A continuous-wear programme was begun. The patient had two episodes of nonulcerative keratitis from which the eye rapidly recovered. A third attempt at continuous-wear was started. At a routine follow-up examination 3 weeks later minor symptoms were reported. There was slight punctate fluorescein staining of the central cornea and slight injection of limbal and bulbar conjunctival vessels. The contact lens fitting was tight (little movement), and the lens front surface was relatively dry. The patient was given a hydrophilic contact lens lubricating solution. The patient slept comfortably that night but awoke in the morning with marked pain in and around the right eye, the sinuses, and teeth. The eyelids were swollen, the eye red and lacri- 


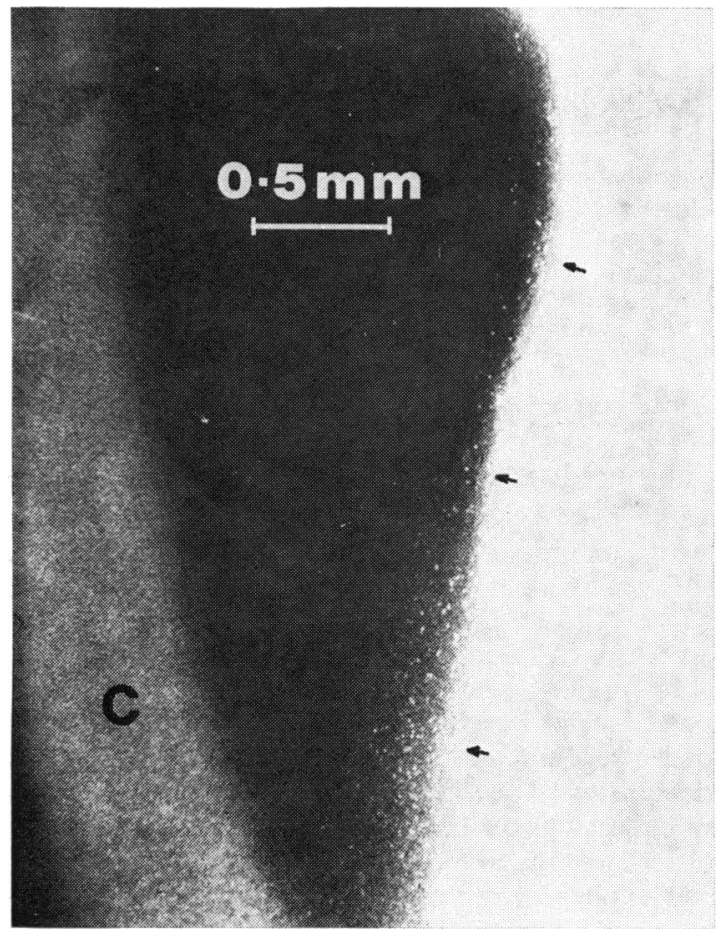

Fig. 1 Endothelial bedewing of the cornea 1 day after the onset of the anterior eye inflammation. With retroillumination from the iris a fine haze consisting of minute particles at the posterior corneal surface, is seen below the pupil. The corneal parallelopiped $(C)$ is shown.

mating. The patient removed the lens and took medication for the facial pain.

The symptoms had very slightly abated when she was examined the following day. The left eye was normal. The right eye presented a typical 'red-eye' reaction associated with continuous contact lens wear. ${ }^{17} 18$ There was considerable conjunctival and ciliary vessel engorgement. There was no fluorescein staining of the epithelium but the cornea was oedematous, and there was a dense infiltrate in the anterior half of the stroma across the entire cornea. There were inflammatory cells (grade 1) in the anterior chamber, but the intraocular pressure was normal. There were fine dust-like particles (measured from the photographs to be approximately $10 \mu \mathrm{m}$ in diameter) scattered over the posterior surface of the endothelium, giving a widespread bedewing appearance $^{19}$ (Fig. 1). There were no large keratic precipitates. The corneal endothelium was irregular in contour, showing numerous round, black areas (approximately $50 \mu \mathrm{m}$ in diameter) similar in appearance to corneal guttae (Figs. 2, 3). When viewed with a narrow slit-lamp beam these black

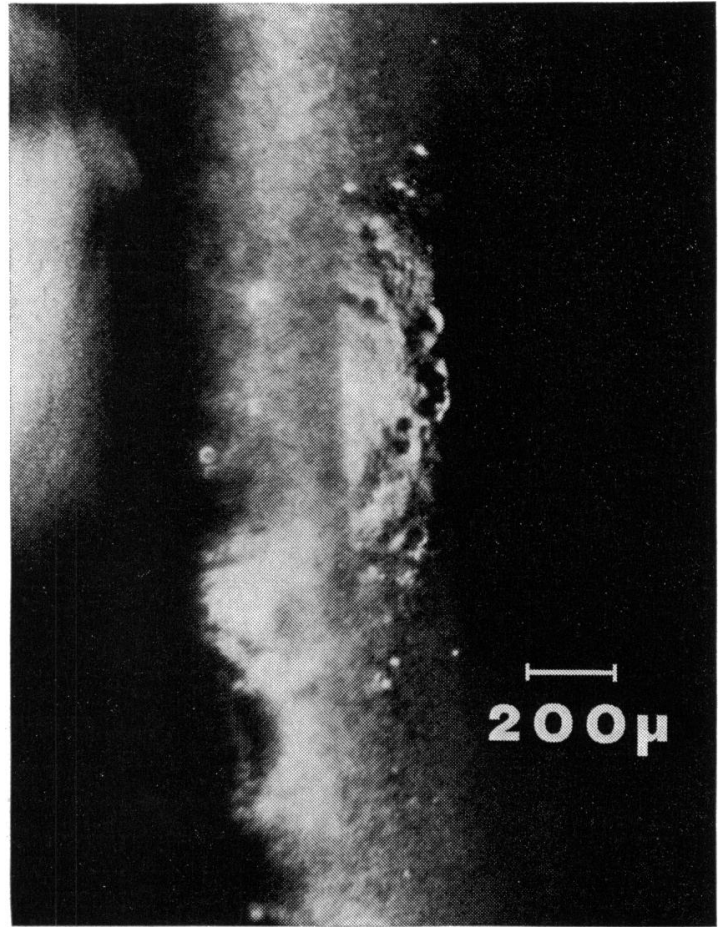

Fig. 2 Numerous corneal guttae are seen at the temporal midperipheral cornea by specular reflection. These were not present before the inflammatory reaction, and they disappeared between 4 and 11 days after onset of the inflammation.

holes appeared as depressions in the endothelial contour with a raised rim (Fig. 2). These guttate areas were not present before this episode.

On the fourth day after onset of the 'red eye' minor symptoms persisted. The cornea was less oedematous and the stromal infiltrate considerably reduced. The corneal endothelium was less irregular in contour and the guttate appearances much less numerous. There were very few inflammatory cells in the anterior chamber, and a small area of endothelial bedewing was present on the inferior cornea.

One week later the corneal infiltrate had almost disappeared, the guttate endothelial changes were absent, and the eye was quiet.

Two days later the patient resumed continuous wear with the original contact lens. There was no sign of any endothelial changes during the subsequent year of successful lens wear.

\section{Discussion}

Acute anterior eye inflammation has been previously reported with therapeutic contact lenses ${ }^{17}$ and with 


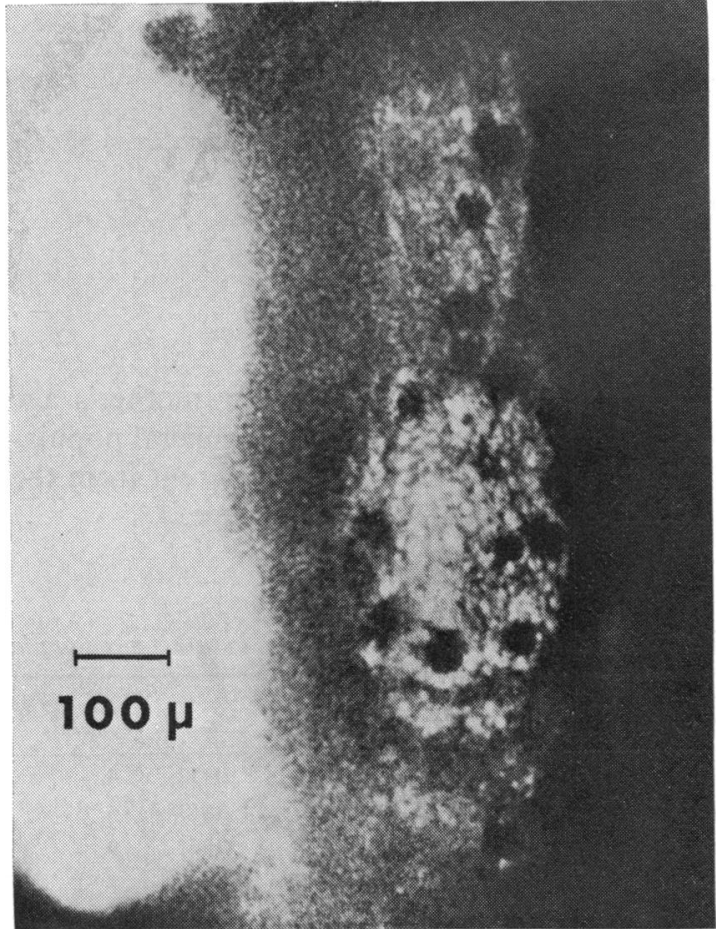

Fig. 3 A different area of the temporal cornea, at higher magnification than Fig. 2, showing guttate endothelial changes.

tight fitting continuously worn lenses. ${ }^{18}$ In these instances this reaction appears to be associated with the entrapment of proteinaceous debris, which can be readily observed with low magnification on the slit-lamp. In this case the red-eye episode was accompanied by all the classical signs of anterior eye inflammation and, in addition, endothelial bedewing and guttate endothelial changes.

The rapid appearance and subsequent disappearance of the guttate changes is curious. The guttae were not present before this episode; they were present one and a half days later, were diminished by the fourth day, and absent by the eleventh day.

Whether these guttate changes are best described as endothelial oedema, preguttae, or even pseudoguttae is not certain. Inomata and Smelser ${ }^{15}$ noted during experimentally induced uveitis in rabbits that the guttate changes they observed were produced by gaps which opened up between Descemet's membrane and the endothelium, and that these gaps were filled with Descemet's membrane-like material and fine fibrils. Whether the guttate changes in this patient had the same composition is unknown. What is clear is that the guttate changes observed are similar in appearance, size, and distribution to those observed in primary endothelial dystrophy, and therefore almost certainly represent accumulations anterior to the endothelium. Whether disturbance of the endothelium was the stimulus for the preendothelial accumulations is speculation, but it is reasonable to assume that both the bedewing and the guttate changes were consequences of the anterior eye inflammation.

\section{References}

1 Feeney ML, Garron LK. Descemet's membrane in the human peripheral cornea. In: Smelser GK, ed. The Structure of the Eye. London: Academic Press, 1961: 367-80.

2 Wolter JR, Larson BF. Pathology of cornea guttata. Am J Ophthalmol 1959; 48: 161-9.

3 Wolter JR. Secondary cornea guttata. Am J Ophthalmol $1960 ; 50$ : 17-25.

4 Wolter JR. Secondary cornea guttata in interstitial keratopathy. Ophthalmologica 1964; 148: 289-95.

$5 \mathrm{Chi} \mathrm{HH}$, Teng CC, Katzin HM. Histopathology of corneal endothelium. Am J Ophthalmol 1962; 53: 215-35.

6 Rodrigues MM, Mulberger RD. Alterations of Descemet's membrane in interstitial keratitis. Am J Ophthalmol 1976; 81: 773-85.

7 Irvine AR, Irvine Jr AR. Variations in normal human corneal endothelium. Am J Ophthalmol 1953; 36: 1279-85.

8 Irvine Jr AR. Pathology of the corneal endothelium. In: King JH, McTigue JW, eds. The Corneal World Congress. Washington: Butterworths, 1965: 65.

9 Duke-Elder S. System of Ophthalmology. London: Kimpton, 1965: 8: 713-20.

10 Stocker FE. Clinical management of corneal dystrophies. In: King JH, McTigue JW, eds. The Corneal World Congress. Washington: Butterworths, 1965: 139.

11 Svedburgh B. Effects of artificial IOP elevation on the corneal endothelium in the vervet monkey. Acta Ophthalmol $(K b h)$ 1975; 53: 839-55.

12 Berliner ML. Biomicroscopy of the Eye. New York: Hoeber, 1943: 416, 494.

13 Grayson M. Degenerations, dystrophies and edema of the Cornea. In: Duane TD, ed. Clinical Ophthalmology. Maryland: Harper and Row, 1978.

14 Brandreth RH. Clinical Slitlamp Biomicroscopy. California: Blaco, 1978: 78.

15 Inomata $H$, Smelser GK. Fine structural alterations of corneal endothelium during experimental uveitis. Invest Ophthalmol Visual Sci 1970; 9: 272-85.

16 Holden BA, Zantos SG. High magnification photography with the slitlamp. In: Brandreth RH. Clinical Slitlamp Biomicroscopy. California: Blaco, 1978.

17 Dohlman CH, Boruchoff A, Mobilia EF. Complications in the use of soft contact lenses in corneal disease. Arch Ophthalmol 1973; 90: 367.

18 Zantos SG, Holden BA. Ocular changes associated with continuous wear of contact lenses. Aust $J$ Optometry 1978; 61: 418-26.

19 McMonnies CW, Zantos SG. Endothelial bedewing of the cornea in association with contact lens wear. $B r$ Ophthalmol 1979; 63: 478-81. 